\title{
Limited inner ear morphogenesis and neurosensory development are possible in the absence of GATA3
}

\author{
JEREMY S. DUNCAN ${ }^{1}$, KIM-CHEW LIM ${ }^{2}$, JAMES D. ENGEL ${ }^{2}$ and BERND FRITZSCH ${ }^{*}, 1$ \\ ${ }^{1}$ Department of Biology, University of lowa, lowa and ${ }^{2}$ Department of Cell and Developmental Biology, \\ University of Michigan Medical School, MI, USA
}

\begin{abstract}
Haploinsufficiency of Gata3causes hypoparathyroidism, deafness and renal dysplasia (HDR) syndrome in mice and humans. Gata3 null mutation leads to early lethality around embryonic day (E)11.5, but catecholamine precursor administration can rescue Gata3 null mutants to E16.5. At E11.5, GATA3 deficiency results in the development of an empty otocyst with an endolymphatic duct. However, using rescued mice we found that some morphogenesis and neurosensory development is possible in the ear without Gata3. Extending previous studies, we find that at E16.5, Gata3 mutant inner ears can undergo partial morphogenesis and develop an endolymphatic duct, a utricular and saccular recess, and a shortened cochlear duct. In addition to the obvious morphogenic aberrations, these studies demonstrate that a subset of neurons develop and connect a fragmented sensory patch of MY07A-positive hair cells to the vestibular nuclei of the brainstem. In situ hybridization studies reveal altered expression of several transcription factors relevant to ear development and we hypothesize that this may relate to the observed dysmorphia and restricted neurosensory development. While a cochlear duct can form, there is no concurrent cochlear neurosensory development, observations consistent with specific hearing defects encountered by HDR patients and mice with Gata3-associated expression alterations. Gata3 null mutant phenocopies the otic maldevelopment (cochlear duct formation in the absence of neurosensory development) seen in Foxg1cre mediated conditional deletion of microRNA processing enzyme, Dicer1. Finally, while GATA3 is expressed in the developing vestibulocochlear efferent (VCE) neurons, and its absence in the null mutants disrupts VCE projections to the ear, loss of GATA3 does not affect VCE progenitor cell migration.
\end{abstract}

KEY WORDS: Gata3, inner ear, ear morphogenesis, ear neurosensory development

\section{Introduction}

The inner ear starts as the otic placode, a thickening of ectoderm adjacent to the hindbrain. The otic placode invaginates to form a vesicle that undergoes morphogenesis and histologic differentiation to become a membranous labyrinth housing the five vestibular sensory epithelia, the organ of Corti, and their connecting neurons. Targeted mutations of genes in the mouse have now identified many genes necessary for inner ear development. However, several of these genes have syndromic effects resulting in early embryonic lethality, preventing the study of their role in the late development of the inner ear, including the zinc finger protein GATA3.

The GATA family of transcription factors binds to the DNA sequence, $A / T$ GATA $A / G$, in eukaryotes. Of the six mammalian
GATA proteins, only GATA2 and GATA3 are expressed in the central nervous system and inner ear (Nardelli et al., 1999). GATA3 is also involved in the development of the nephric duct (Grote et al., 2006), trophoblast (Ma et al., 1997), sympathetic nervous system (Lim et al., 2000), lens (Maeda et al., 2009), mammary luminal cells (Asselin-Labat, 2007), skin and hair cells (Kaufman et al., 2003), and T lymphocytes (reviewed in Ranganath and Murphy, 2001). GATA3 in humans has also been linked to breast cancer invasiveness (Fang et al., 2009). Mice heterozygous for Gata3 survive until adulthood but suffer from hearing loss

\footnotetext{
Abbreviations used in this paper: FBM, facial branchial motoneuron; HDR, hypoparathyroidism, deafness and renal dysplasia syndrome; ISH, in situ hybridization; VCE, vestibulo-cochlear efferent.
}

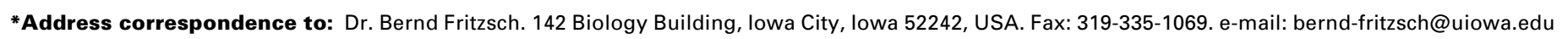


(van der Wees et al., 2004). Likewise, humans heterozygous for GATA3 mutations resulting in a non-functional protein suffer from the congenital disorder Hypoparathyroidism, sensorineural Deafness and Renal dysplasia (HDR) syndrome (Van Esch et al., 2000). Additionally, GATA3 gene duplication can result in HDR syndrome (Bernardini et al., 2009) indicating that a precise level of GATA3 protein is required for the development of multiple systems, including the ear.

Gata3 is one of a few genes expressed broadly in the otic placode as early as embryonic day 8 [E8] (Lawoko-Kerali et al., 2004). By E10.5 its expression is restricted to nearly all prosensory regions, except the future saccular area (Karis et al., 2001). Gata3 expression remains in sensory and non-sensory cells of all epithelia except the saccule until E18.5 where it becomes restricted in the vestibular epithelia to the cruciate eminence, and striola of the utricle (Karis et al., 2001). Expression of Gata3 throughout the organ of Corti remains long-term (van der Wees et al., 2004). GATA3 has been detected in the developing spiral ganglion neurons at E10.5 (Lawoko-Kerali et al., 2004), and Gata3 mRNA persists in these neurons throughout adulthood (van der Wees et al., 2004). In addition to its expression in the inner ear, Gata3 is also expressed in the vestibulo-cochlear efferent (VCE) neurons. VCE cell bodies are located in rhombomere 4 of the hindbrain, and Gata3 with Gata2 are the earliest known genes to be differentially expressed in the VCEs and not in the adjacent facial branchial motoneurons (FBM); out of which VCEs seem to develop (reviewed in, Simmons et al., 2011).

Previous work on Gata3-deficient mice showed that the inner ear halted development at the level of an empty otocyst with the endolymphatic duct being the only discernable structure (Karis et al., 2001). However, early embryonic lethality around E11-12 hampered investigations into the effects of Gata3loss-of-function mutation on later inner ear development, including its effect on neurosensory development and morphogenesis. Feeding pregnant dams catecholamine intermediates allows the embryos to survive until E16.5 and rarely until E18.5 (Lim et al., 2000). We show here that these later stage Gata3 null embryos develop inner ears beyond the previously reported empty vesicle, forming a superior division with sensory hair cells, and a cochlear duct. Neurons also form that extend processes to the vestibular nuclei of the hindbrain. In contrast, the cochlea is devoid of innervation and hair cell formation. The VCE population of Gata3-deficient embryos exhibit normal cell body migration, but altered axonal projection. The complete absence of GATA3 is thus compatible with rudimentary vestibular morphogenesis and neurosensory development, but GATA3 is required for cochlear neurosensory development.

\section{Results}

\section{Inner ear formation}

We present here data on Gata3 null mice which have been rescued to a later embryonic stage (E16.5) than previously described, by giving pregnant dams catecholamine intermediates. The most developed ears (Fig. 1) had a cochlear duct forming a finger-like postero-ventral extension, in addition to structures that we tentatively label as a saccular and utricular recess. Multiple patches of sensory epithelium with MYO7Apositive hair cells were only found in the saccular recess (Fig. $\left.1 A^{\prime}\right)$, identified based on its connection to the cochlea via a ductus reuniens, and the origin of the endolymphatic duct (Fig. 1C). The saccular macula was innervated as seen by tubulin staining (Fig. 1A). Additional isolated hair cells were scattered throughout the malformed saccular recess (Fig. 1A'). These hair cells had stereocilia projecting into the lumen, and were innervated (Fig. 1B-B'”). There was no indication of innervation or hair cell formation in the cochlear duct (Fig. 1A"). As a comparison we have also 3D reconstructed the inner ear from an E15.5 Dicer1 conditional knockout using Foxg1cre. This is the only other known mutation to completely eliminate cochlear neurosensory development while
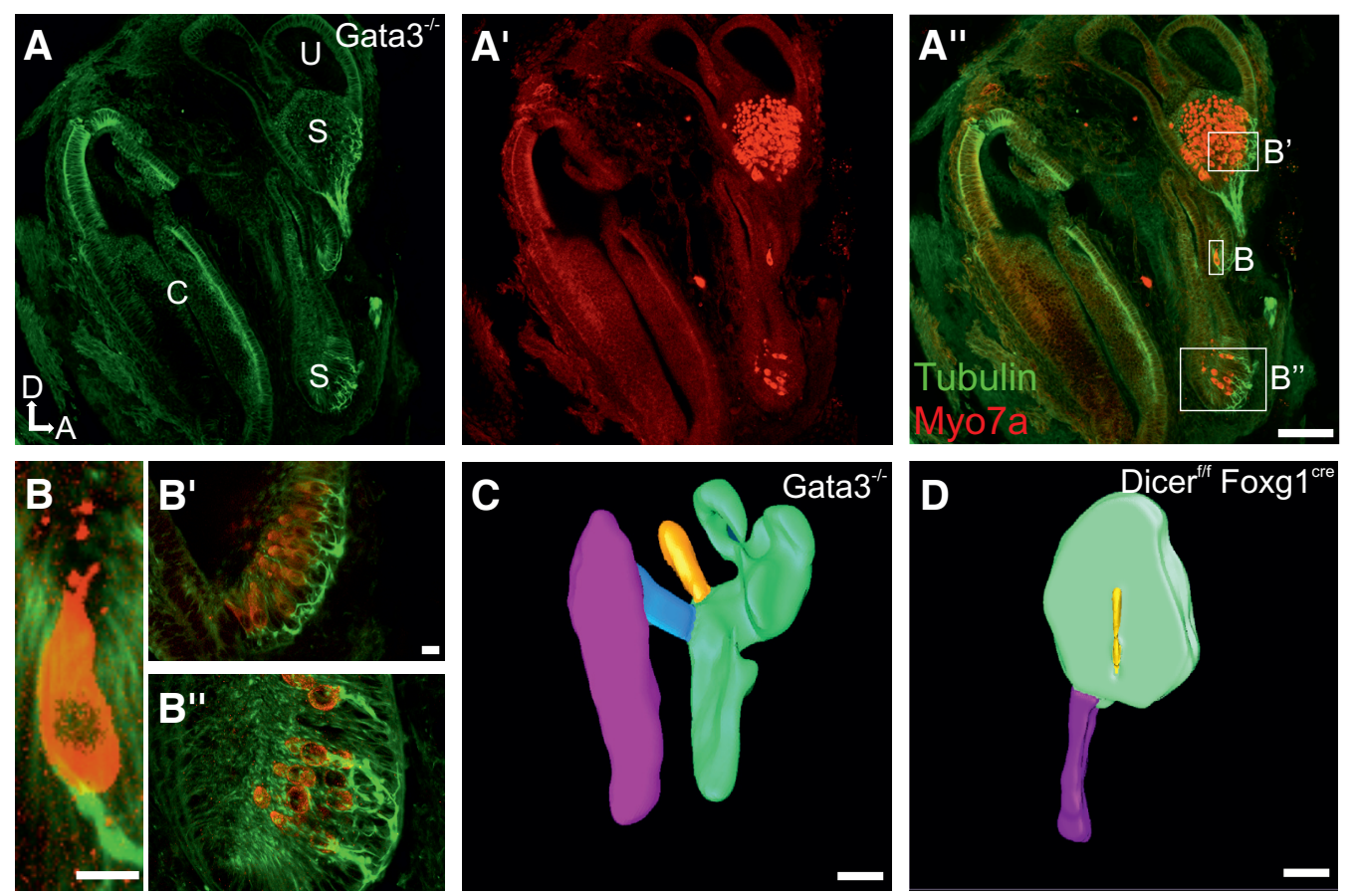

Fig. 1. Limited morphogenesis and neurosensory development are possible in the absence of GATA3. (AB") Whole mounted E16.5 Gata3\% ear; green, Tubulin; red, MYO7A. (A-A") the cochlea $(C)$ can be seen as a finger like projection next to the saccule (S). The saccule has MYO7A-positive hair cells, while the cochlea does not. $A^{\prime \prime}$ boxes represent areas magnified in $B$ $B^{\prime \prime}$. (B-B') Vestibular hair cells in close contact with neurons. Images are of a smaller plane of section than $A^{\prime \prime}$. (C) $3 D$ reconstruction of the ear in $A, B$. (D) $3 D$ reconstruction of conditionally deleted Dicer1 using Foxg1cre. (C,D) Cochlear duct is represented in (magenta); ductus reuniens (b/ue); endolymphatic duct (gold); vestibular portion (green). Scale bars, $(A, C, D)$ $100 \mu \mathrm{m} ;\left(B, B^{\prime}\right) 10 \mu \mathrm{m}$. 

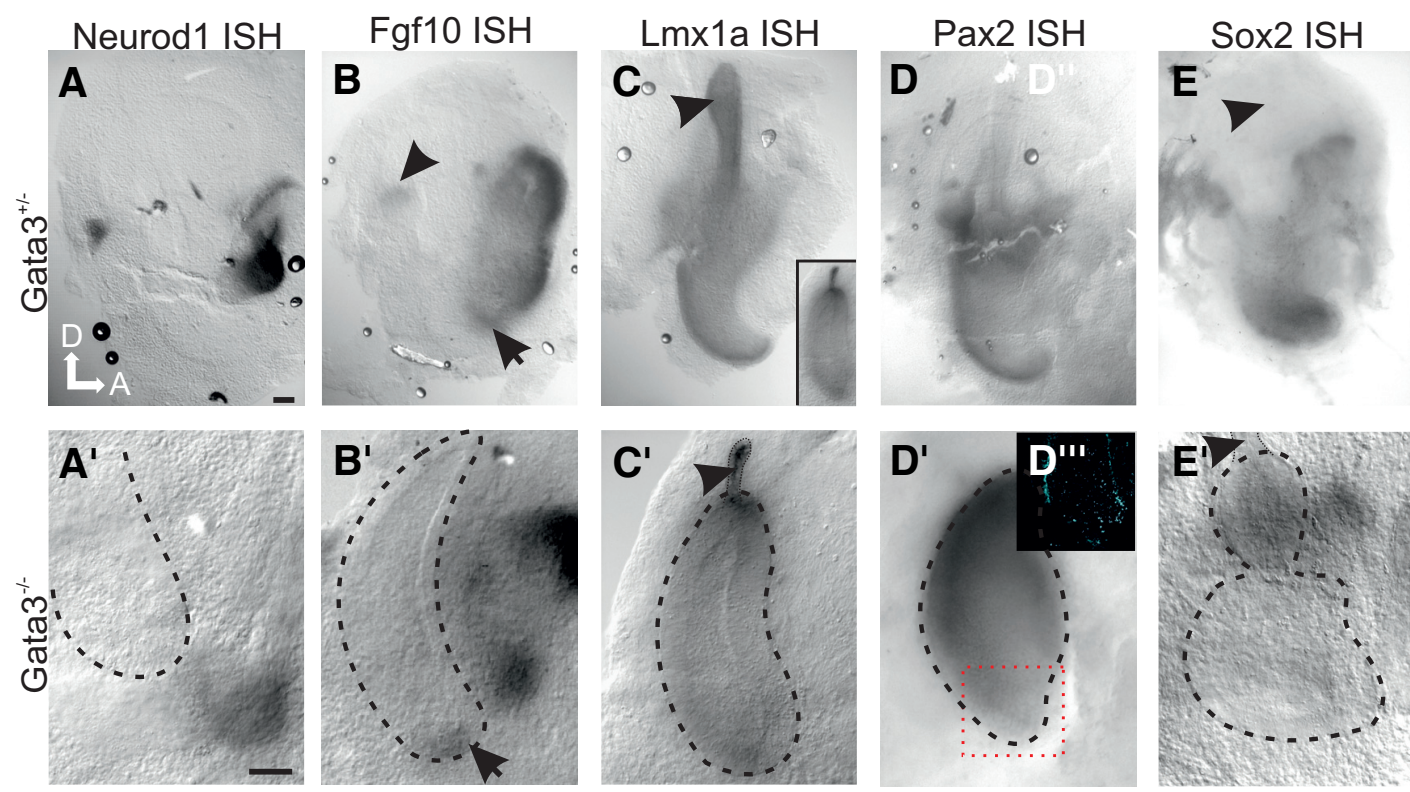

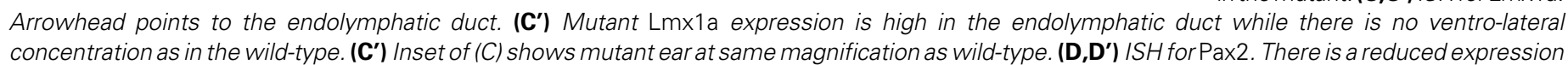
in the ventral ear of the mutant, and an increased expression in the dorsal portion. Red box showing area magnified in $D^{\prime \prime}, D^{\prime \prime \prime}$. (D",, $\left.\mathbf{D}^{\prime \prime \prime}\right)$ PSVue staining showing apoptotic cells in ventral portion of mutant ear. There is no positive indication for apoptotic cells in the wild-type $D^{\prime \prime}$. (E,E') /SH for Sox2, arrowhead points to the endolymphatic duct. Dorsal is up and anterior is to the right for all images. Dotted black line in $A^{\prime}-E^{\prime}$ indicates outline of ear, verified using various focal planes and DIC imaging. Scale bar in (A) indicates $100 \mu \mathrm{m}$ for (A-E). Scale bar in (A') indicates $100 \mu \mathrm{m}$ for $A^{\prime}-E^{\prime}$.

a partial cochlear duct remains (Fig. 1D, Kersigo et al., 2011). There is another mutant the Sox2 LCC mouse that displays loss of all cochlear sensory epithelia, but has not been fully investigated with respect to innervation (Kiernan et al., 2005).

We also examined some of the genes known to be necessary for inner ear neurosensory development as well as morphogenesis beyond those previously described (Lillevali et al., 2006). Previous work showed that Neurod1 is expressed in the differentiating inner ear afferent neurons (Jahan et al., 2010). Without Gata3 some Neurod1-positive cells formed. However, their location was ventro-anterior to the smaller otocyst, and not anterior halfway between dorsal and ventral as in the wild-type embryo (compare Fig. 2A with Fig. 2A'). These cells most likely represent the remaining vestibular neurons giving rise to afferent connections as traced in later stages (Fig. 3D). Fgf10 has previously been shown to be expressed in all three canal cristae, anterior cochlear anlagen and sensory neurons (Pauley et al., 2003). Previous studies have shown that in the absence of GATA3 there is a complete lack of Fgf10 expression in the otic vesicle at E9.5, and by E11.5 there is reduced expression (Lillevali et al., 2006). Our in situ data demonstrate that Fgf10 was expressed at E12.5 in Gata3 null embryos in the ear and vestibular ganglia. However, there was no detectible expression in the presumptive canal cristae as seen in wild-type embryos (compare Fig. 2B with Fig. $2 \mathrm{~B}^{\prime}$ ). Moreover, the presumptive cochlear expression was less distinctly organized compared to wild-type embryos. Lmx1a is expressed in the otic placode and necessary for segregation of sensory epithelia (Nichols et al., 2008). In the absence of GATA3, Lmx1a was expressed in the endolymphatic duct but showed diffuse expression in the remaining ear (Fig. 2C'). This is in contrast to the wild-type ear where the concentrated expression in the lateral wall of the cochlea was previously described (Fig.
2C; (Nichols et al., 2008). Pax2 is initially expressed in the nonsensory areas of the cochlear duct and later in development in hair cells (Bouchard et al., 2010). In the Gata3 mutants there was a high level of Pax2 expression in the dorsal inner ear with a gradient toward diminished expression ventrally (Fig. 2D'). This was in contrast to the high level of expression in the lateral cochlear duct of wild-type embryos (Fig. 2D). Closer examination revealed that this ventral reduction in expression of Pax2 in the Gata3 null mutant may be related to cell death in this area as revealed with PSVue staining (compare Fig. 2D" with Fig. 2D'"), which marks degenerating cells in the ear and elsewhere (Kersigo et al., 2011). In wild-type embryos, Sox2 was expressed throughout the cochlear duct, most prominently in the ventral tip (Fig. 2E). In the Gata3 null ear, there was a lack of ventral Sox2 expression while the dorsal region below the endolymphatic duct was Sox2positive (Fig. 2E'). These changes indicate that expression of these genes is altered, thus disrupting the coordinated expression of patterning genes needed for normal ear development.

\section{Inner ear afferent development}

Lipophilic dye tracing from the brainstem to the ear showed afferents projecting to only a single vestibular epithelium of the ear (Fig. 3D,E). From this tracing, we were able to identify the presence of a vestibular ganglion (Fig. 3F). Lipophilic dye tracing from the ear to the brainstem also labeled facial branchial motoneurons (FBM) as the facial nerve tightly wraps around the small ear of the Gata3 mutant, vestibulo-cochlear efferents (VCEs), afferent fibers to the vestibular nuclei, and fibers to the solitary tract were inadvertently labeled in addition (Fig. 4). In the wildtype embryo, we traced vestibular afferents through the superior vestibular nucleus, and via the inferior cerebellar peduncle, into the cerebellar anlage (Fig. 4A). These vestibular afferents will 
Fig. 3. GATA3 absence results in altered inner ear innervation. (A) E16.5 Gata3 ${ }^{+/+}$; (B-E) E16.5 Gata3\%; (F) E14.5-Gata3\%. (A) Lipophilic dye was inserted into the ipsilateral rhombomere 4 to label the facial nerve (FN) and VCEs and afferents to the ear. Six sensory epithelia can be distinguished; three semicircular canals (horizontal, anterior, posterior), two gravistatic organs (utricle, saccule), and the cochlea. In the wild-type embryo, the FN can be seen coursing around the ear between the vestibular portion and the cochlear portion wrapping medially to laterally around the anterior edge of the ear, then continuing posteriorly. The geniculate ganglion (GG) can be seen where the cell bodies of the greater petrosal nerve and chorda tympani are located. (C) mutant with lipophilic dye placed into the contralateral rhombomere 4. Because VCES are the only motor neurons to project contralaterally in rhombomere 4 the FN should be free of labeling. The efferents in the mutant (B,C) are seen coursing through the vestibular ganglion (VG) along the ventral portion
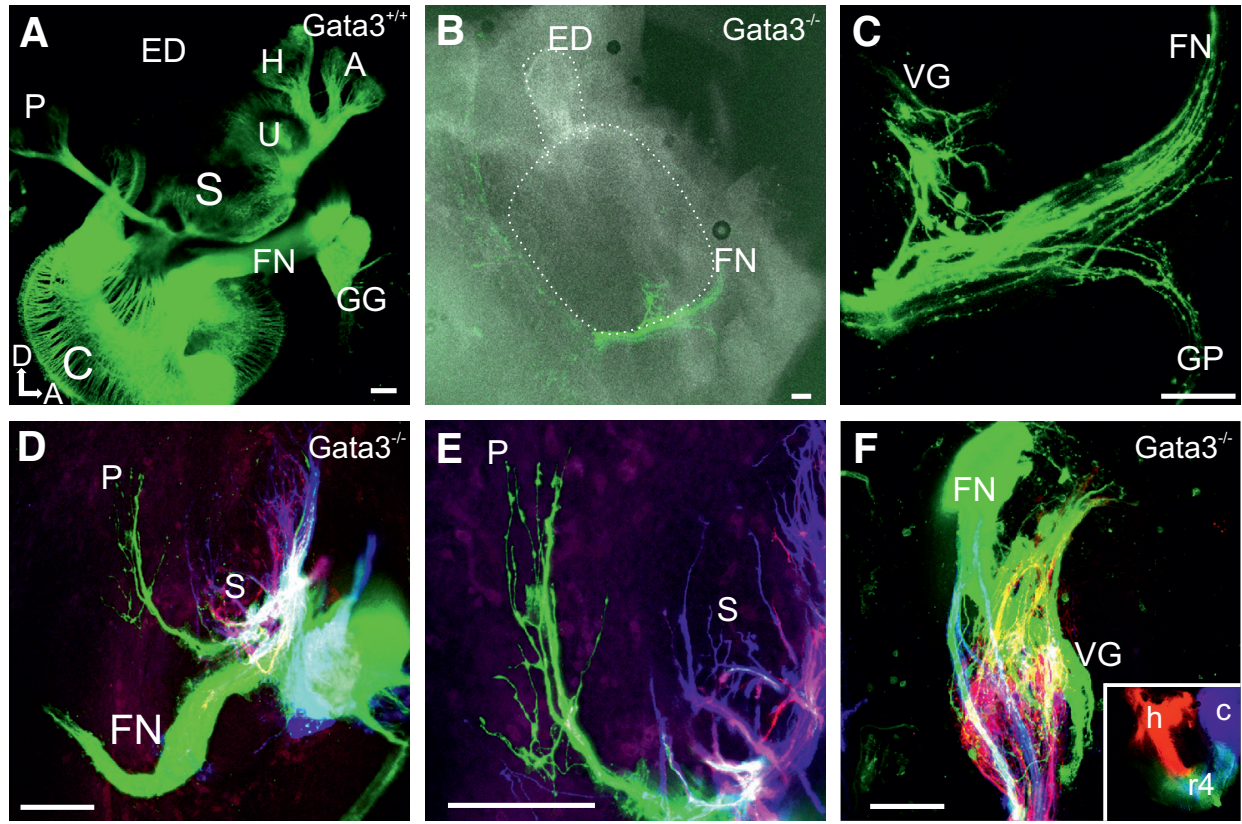
of the ear to continue in all branches of the

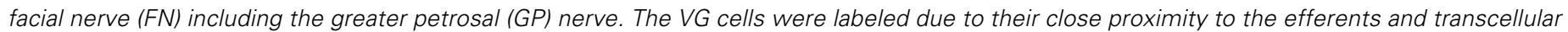

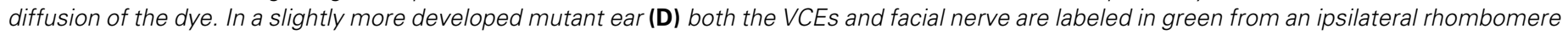

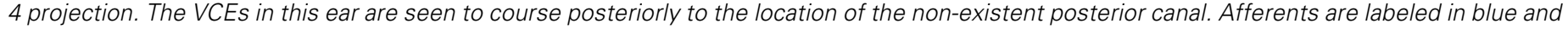

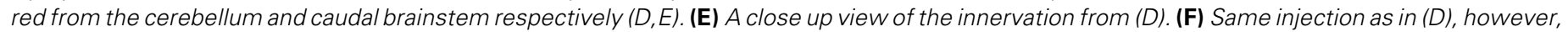

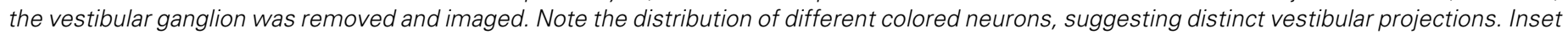
shows location of dye placement for (D-F) in the hindbrain; 4 , rhombomere 4; cerebellum; h, caudal hindbrain. Scale bars: 100 um.

terminate later in the granular layer of the nodule and the caudal part of the uvula of the vermis (Maklad et al., 2010). In the Gata3 mutant, only a single fiber could be traced into the cerebellar anlage at this early stage (Fig. 4D, white arrow). Several Gata3 null mutants showed no labeling to or from the ear, indicating variability in the mutant phenotype (data not shown).

\section{Vestibulo-cochlear efferent nerve development}

The VCEs are a unique population of hindbrain motor neurons that project to the inner ear and seem to have obtained access to the otic hair cells after the otic vesicle evolved (reviewed in, Simmons et al., 2011). These neurons are thought to regulate the intensity of sound reaching the brain by modulating the outer hair cells and inner hair cell afferents (Guinan and Stankovic, 1996). VCEs are the only efferent neurons to arise from rhombomere 4 and project contralaterally. The VCEs express GATA3, and project normally in Gata3heterozygotes (Karis et al., 2001). It was hypothesized (Karis et al., 2001) that the VCEs may project with the facial nerve in the absence of GATA3. Due to the course of the facial nerve around the inner ear we could label simultaneously both the VCEs and the facial nerve and could analyze their distribution in the hindbrain (Fig. 4). Gata3 is not expressed in the facial branchial motoneuron (FBM) population at any age (Karis et al., 2001), and loss of GATA3 does not affect FBM migration (compare Fig. 4A with Fig. 4D). The contralateral VCE projection in Gata3 null mutant mice was reduced (compare Fig. 4B,C with Fig. 4E,F). The peripheral projection of contralateral VCEs was disrupted, with only a few fibers reaching the contralateral ear. However, most contralateral fibers were projecting along the facial and greater petrosal nerves (Fig. 3B,C) as compared to normal efferent and facial projection patterns (Fig. 3A).

We also examined cell body migration of VCE in the hindbrain in these later stage embryos using in situ hybridization for well characterized markers of VCEs (Simmons et al., 2011). Using probes for Fgf10 and Unc5c (Fig. $4 \mathrm{H}, \mathrm{I}$ ), we found no obvious change in the cell body distribution (compare with Fig. 4G).

\section{Discussion}

The present study expands previous work (Karis et al., 2001, Lillevali et al., 2006) and assessed for the first time the phenotype of the inner ear and its innervation in the absence of Gata3 at later embryonic stages than have been previously characterized. Our data confirm previous findings that there is variability between and within animals in the development of the Gata3null inner ear (Karis et al., 2001, Lillevali et al., 2006). However, we show here that the inner ear can develop much further in the absence of GATA3 than previously thought. Our data demonstrate that sensory hair cells form in some Gata3null mice, and aggregate in a single recess that we tentatively identified as the saccular recess, an assumption based on the fact that the saccule is the only area of the developing ear that does not show GATA3 expression (Karis et al., 2001). As in wild-type littermates, a ductus reuniens and endolymphatic duct can be identified in the Gata3 null mutants. Some hair cells form in the absence of Gata3 in the ear and are innervated by the remaining ganglia that project to the vestibular nuclei. The saccule normally does not express Gata3 (Karis et al., 2001) and formation of a saccule in the Gata3 null mice is consistent with the former observation: no Gata3 expression, no effect of loss of Gata3. In contrast, the postero-ventral duct, which we identified as the 
cochlear recess, was devoid of hair cells.

Despite the formation of two vestibular and one cochlear recess, there is no semicircular canal formation in the Gata3 null mutants. The absence of canal formation may be due in part to the regulation of Fgf10by GATA3 (Lillevali et al., 2006), but the phenotype is more severe than that of Fgf10 null mice (Pauley et al., 2003). Thus, GATA3 must be interacting with other factors needed for canal formation that remain to be determined. Some candidate genes could be Bmp4, Jag1, Lmo4, Lmx1a, and Foxg1 because of their known or suspected function in canal development (Nichols et al., 2008). We suspect that the early widespread expression in the growing canal plate and not the later limited expression in the cruciate eminence (Karis et al., 2001) is responsible for the absence of canal formation.

The altered expression of some known genes involved in ear morphogenesis could be due to the immediate loss of GATA3, or a consequence of morphogenetic defects. Because the ears of Gata3 null mice are substantially smaller in size than that of their wild-type counterparts, this could cause altered expression of genes dependent upon gradients of various diffusible factors recognized for their role in ear development (Ohyama et al., 2007). Decreased expression in the ventral portion of the ear where the cochlear out pouching occurs in the Gata3 mutants could be attributed to increased cell death (Fig. 2D"').
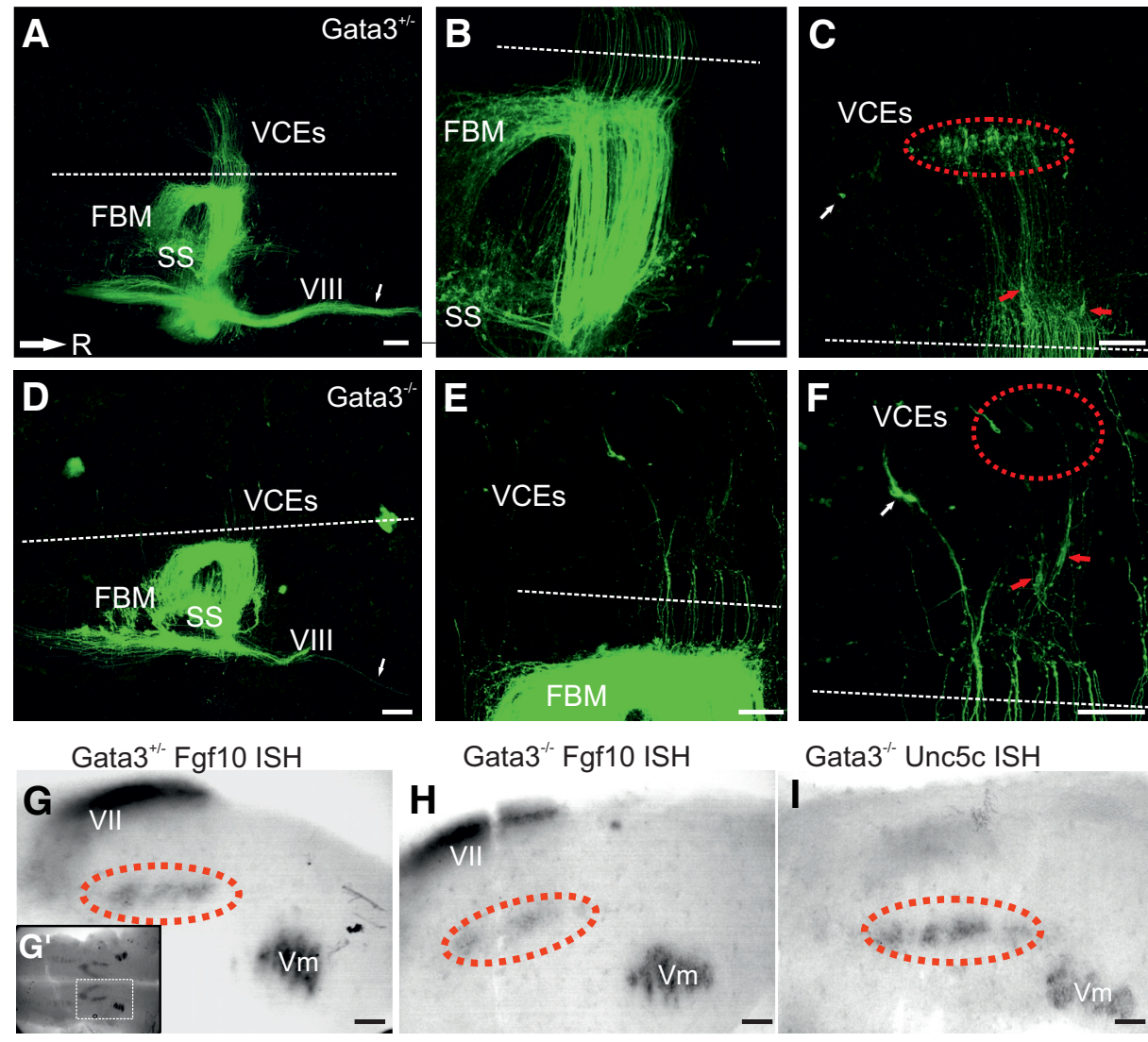

$\mathrm{Gata3}^{-/ 2}$ Fgf10 ISH
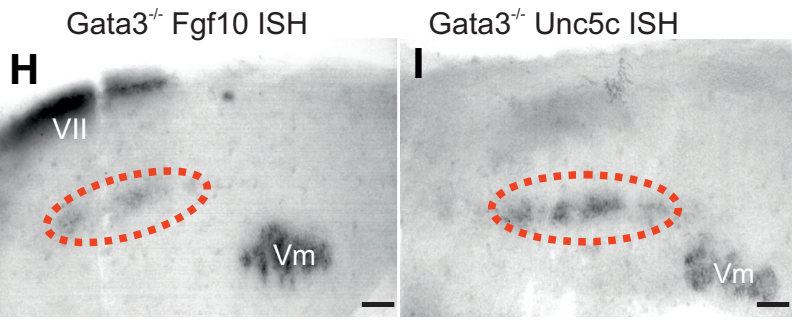

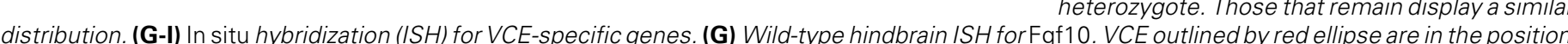

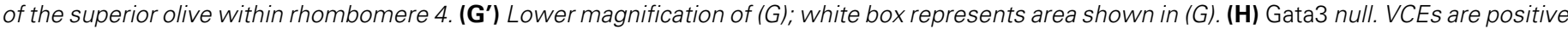

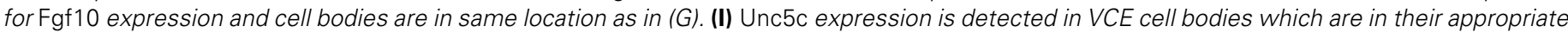

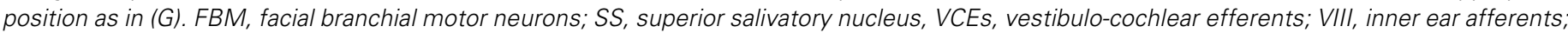
$\mathrm{Vm}$, trigeminal motor nerve. White dotted line indicates the floor plate. Rostral is to the right. Scale bars: A, D, $200 \mu \mathrm{m} ; \mathrm{B}, \mathrm{C}, \mathrm{E}-\mathrm{I}, 100 \mu \mathrm{m}$. 
(P27 ${ }^{\text {kip1}}$ ) to be downregulated when Gata3 was knocked-down. CDKN1b is known to move organ of Corti progenitor cells out of the cell cycle, and its downregulation causes additional rounds of cell division.

Our data support the previous findings that in the absence of GATA3, VCEs are reduced in their projection across the midline and fail to target the ear, thus adding to the growing body of evidence that GATA3 facilitates neuronal guidance across phyla. For example, another Drosophila GATA3 ortholog Grn appears to be necessary for the specification of a subset of neurons in the fly as well as necessary for their correct guidance (Garces and Thor, 2006). However, we show here that these neurons are not absent or fail to migrate their soma to the correct location in the hindbrain, indicating that GATA3 is not essential for these aspects of neuronal development of VCEs. In order to ascertain whether loss of GATA3 in the VCEs is causing the mis-projection or if this is due to the absence of afferents such as in the Neurog 1 null mice (Ma et al., 1998), a conditional deletion of Gata3 in either the ear or the brainstem is needed to discriminate between cell autonomous VCE effects from the effects mediated by their guidance along afferents, lost or reduced in Gata3 null mice.

\section{Materials and Methods}

\section{Mice}

The generation and characterization of Gata3 knockout heterozygous (Gata3+/-) mice has been previously reported (Pandolfi et al., 1995). Gata3+/- animals (CD1 outbred) were intercrossed and the dams were given ad libitum drinking water containing catechol intermediates, as described previously (Kaufman et al., 2003, Lim et al., 2000). How catechol intermediates work to prevent premature death is still not clear, but is thought to relate to retention of some brainstem reticular function essential for homeostasis (Lim et al., 2000). It has been shown that this treatment does not have any effect on ear development (Maison et al., 2010). Noon on the day of vaginal plug visualization was deemed E0.5. Embryos from timed pregnancies were fixed in $4 \%$ paraformaldehyde (PFA). Yolk sacs were collected for PCR genotyping as previously described (Pandolfi et al., 1995).

35 embryos were examined in this study; 13 were of Gata3-/-genotype. Dicer1 conditional mouse generation, breeding, and genotyping was performed as previously reported (Kersigo et al., 2011). Animal treatment was approved by the University of Michigan IACUC (Approval 8611) and University of lowa IACUC (ACURF 0804066).

\section{Neuronal tracing}

Inner ear innervation was labeled with lipophylic (NeuroVue) dyes (Molecular Targeting Technologies; MTTI). These dyes were placed into specific areas for selective labeling of nerve fibers as shown in (Duncan et al., 2011). Dyes were placed into the cerebellum and caudal hindbrain for selective labeling of vestibulo-cerebellar and vestibulo-spinal nerves as described (Maklad et al., 2010). Dye was placed in the contralateral or ipsilateral rhombomere 4 for pure contralateral vestibulo-cochlear efferent or combined vestibulo-cochlear efferent and facial nerve, respectively. Dye was also placed into the ear to label vestibulo-cochlear efferent, facial, and vestibulo-cochlear afferent projections to the brainstem. The preparations were then incubated in 4\% PFA at 36 degrees for 2-4 days depending on the age of the embryos. After dye diffusion either the hindbrain or ear was dissected out, placed on a glass slide with glycerol and a cover slip on top to be imaged using a confocal microscope.

\section{Cell labeling}

Hair cells were labeled using MYO7A antibodies 1:500 dilution (Proteus Biosciences) and nerve fibers were labeled using acetylated $\beta$-tubulin antibodies 1:800 dilution (Sigma) as previously described (Duncan et al., 2011). Secondary antibodies (Sigma) were conjugated to either Alexa 543 , or 648; 1:500 dilution. Nuclei were stained with Hoechst dye (Polysciences, Inc.; 1:2000 in PBS for 2 hours), rinsed briefly in PBS and imaged. Apoptotic cells were labeled with PSVue (Molecular Targeting Technologies; MTTI) as in (Kersigo et al., 2011). Briefly, ears were rinsed in PBS for $10 \mathrm{~min}$ followed by staining with PSVue, $1 \mu \mathrm{m}$ diluted in PBS, for 45 minutes. Ears were then rinsed in PBS for 3 hours and imaged.

\section{In situ hybridization}

In situ hybridization was performed as shown in (Duncan et al., 2011) using an RNA probe labeled with digoxigenin. The plasmids containing the cDNAs were used to generate the RNA probe by in vitro transcription. Dissected ears were dehydrated in $100 \%$ methanol, rehydrated in a graded methanol series, and digested briefly with $20 \mathrm{mg} / \mathrm{ml}$ of Proteinase $\mathrm{K}$ (Ambion, Austin, TX, USA) for $12 \mathrm{~min}$. Then the samples were hybridized overnight at $60{ }^{\circ} \mathrm{C}$ to the riboprobe in hybridization solution containing $50 \%(\mathrm{v} / \mathrm{v})$ formamide, $50 \%(\mathrm{v} / \mathrm{v})$ saline sodium citrate and $6 \%$ $(w / v)$ dextran sulphate. After washing off the unbound probe, the samples were incubated overnight with an anti-digoxigenin antibody conjugated with alkaline phosphatase (Roche Diagnostics $\mathrm{GmbH}$, Mannheim, Germany). After a series of washes, the samples were reacted with nitroblue phosphate/5-bromo, 4-chloro, 3-indolil phosphate (BM purple substrate, Roche Diagnostics $\mathrm{GmbH}$, Mannheim, Germany), which is enzymatically converted to a purple colored product. The ears were mounted flat in glycerol and viewed in a Nikon Eclipse 800 microscope using differential interference contrast microscopy, and images were captured with Metamorph software.

\section{Imaging}

For both immunohistochemistry and lipophilic dye tracing the inner ear or brain was dissected and flat mounted on a slide and covered with glycerol and a coverslip for confocal imaging. Imaging was performed using either Leica TCS SP5 or Leica SPE confocal systems using appropriate filter settings. Images were obtained using the Leica AF software and analyzed using CorelDraw.

\section{$3 D$ reconstruction}

Ears were stained with Hoechst dye and imaged on a Leica SP5 confocal microscope as described above. The z-stack for each ear was loaded into Amira software (Visage Imaging, San Diego, CA.) for 3D reconstruction. To isolate the different inner ear structures segmentation was performed using Amira's segmentation function. This was accomplished by outlining the borders of each structure (visualized by the Hoechst's stain) in every section within the stack. After segmentation, Amira calculated the surface volume and reconstructed the 3D shape of the inner ear.

\section{Acknowledgements}

This work was supported by an NIH grant R01DC005590 to B.F. Imaging was accomplished at the Carver Center for Imaging. We wish to thank the following people for providing plasmids used for our in situ hybridization experiments: Jacqueline Lee (Neurod1), Brigid Hogan (FGF10), Kathrine J Millen (Lmx1a), Maxime Bouchard (Pax2), Kathryn Cheah (Sox2), and Susan Ackerman (Unc5c). We wish to thank Jennifer Kersigo for the breeding and genotyping of the conditionally deleted Dicer1 mice. We thank the University of lowa Office of the Vice President for Research (OVPR) and the College of Liberal Arts and Sciences for their support.

\section{References}

ASSELIN-LABAT, M.L. (2007). Mammary stem and progenitor cells: critical role of the transcription factor Gata-3. M S-Medecine Sciences 23: 1077-1080. BERNARDINI, L., SINIBALDI, L., CAPALBO, A., BOTTILLO, I., MANCUSO, B., 
TORRES, B., NOVELLI, A., DIGILIO, M.C. and DALLAPICCOLA, B. (2009). HDR (Hypoparathyroidism, Deafness, Renal dysplasia) syndrome associated to GATA3 gene duplication. Clin Genet 76: 117-119.

BOUCHARD, M., DE CAPRONA, D., BUSSLINGER, M., XU, P. and FRITZSCH, B. (2010). Pax2 and Pax8 cooperate in mouse inner ear morphogenesis and innervation. BMC Dev Biol 10: 89.

DUNCAN, J.S., KERSIGO, J., GRAY, B. and FRITZSCH, B. (2011). Combining Lipophilic dye, in situ Hybridization, Immunohistochemistry, and Histology. J Vis Expe 49: e2451.

FANG, S.H., CHEN, Y.Z. and WEIGEL, R.J. (2009). GATA-3 as a Marker of Hormone Response in Breast Cancer. J Surg Res 157: 290-295.

FRITZSCH, B., JAHAN, I., PAN, N., KERSIGO, J., DUNCAN, J. AND KOPECKY, B. (2011) Dissecting the molecular basis of organ of Corti development: Where are we now?. Hearing Res (doi:10.1016/j.heres.2011.01.007).

GARCES, A. and THOR, S. (2006). Specification of Drosophila aCC motoneuron identity by a genetic cascade involving even-skipped, grain and zfh1. Development 133: 1445-1455.

GROTE, D., SOUABNI, A., BUSSLINGER, M. and BOUCHARD, M. (2006). Pax 2/ 8-regulated Gata-3 expression is necessary for morphogenesis and guidance of the nephric duct in the developing kidney. Development 133: 53-61.

GUINAN, J.J. and STANKOVIC, K.M. (1996). Medial efferent inhibition produces the largest equivalent attenuations at moderate to high sound levels in cat auditory-nerve fibers. J Acoust Soc Am 100: 1680-1690.

JAHAN, I., KERSIGO, J., PAN, N. and FRITZSCH, B. (2010). Neurod1 regulates survival and formation of connections in mouse ear and brain. Cell Tissue Res 341: 95-110.

KARIS, A., PATA, I., VAN DOORNINCK, J.H., GROSVELD, F., DE ZEEUW, C.I., DE CAPRONA, D. and FRITZSCH, B. (2001). Transcription factor GATA-3 alters pathway selection of olivocochlear neurons and affects morphogenesis of the ear. J Comp Neurol 429: 615-630.

KAUFMAN, C.K., ZHOU, P., PASOLLI, H.A., RENDL, M., BOLOTIN, D., LIM, K.C., DAI, X., ALEGRE, M.L. and FUCHS, E. (2003). GATA-3: an unexpected regulator of cell lineage determination in skin. Genes Dev 17: 2108-2122.

KERSIGO, J., D'ANGELO, A., GRAY, B., SOUKUP, G.A. and FRITZSCH, B. (2011). The role of sensory organs and the forebrain for the development of the craniofacial shape as revealed by Foxg1-cre mediated microRNA loss. Genesis (doi:10.1002/dvg.20714).

KIERNAN, A.E., PELLING, A.L., LEUNG, K.K., TANG, A.S., BELL, D.M., TEASE, C., LOVELL-BADGE, R., STEEL, K.P. and CHEAH, K.S. (2005). Sox2 is required for sensory organ development in the mammalian inner ear. Nature 434: 1031-1035.

LAWOKO-KERALI, G., RIVOLTA, M.N., LAWLOR, P., CACCIABUE-RIVOLTA, D.I., LANGTON-HEWER, C., VAN DOORNINCK, J.H. and HOLLEY, M.C. (2004). GATA3 and NeuroD distinguish auditory and vestibular neurons during development of the mammalian inner ear. Mech Dev 121: 287-299.

LILLEVALI, K., HAUGAS, M., MATILAINEN, T., PUSSINEN, C., KARIS, A. and SALMINEN, M. (2006). Gata3 is required for early morphogenesis and Fgf10 expression during otic development. Mech Dev 123: 415-429.

LIM, K.C., LAKSHMANAN, G., CRAWFORD, S.E., GU, Y., GROSVELD, F. and ENGEL, J.D. (2000). Gata3 loss leads to embryonic lethality due to noradrenaline deficiency of the sympathetic nervous system. Nat Genet 25: 209-212.

MA, G.T., ROTH, M.E., GROSKOPF, J.C., TSAI, F.Y., ORKIN, S.H., GROSVELD, F., ENGEL, J.D. and LINZER, D.I. (1997). GATA-2 and GATA-3 regulate trophoblast-specific gene expression in vivo. Development 124: 907-914.

MA, Q., CHEN, Z., DEL BARCO BARRANTES, I., DE LA POMPA, J.L. and ANDERSON, D.J. (1998). neurogenin1 is essential for the determination of neuronal precursors for proximal cranial sensory ganglia. Neuron 20: 469-482.

MAEDA, A., MORIGUCHI, T., HAMADA, M., KUSAKABE, M., FUJIOKA, Y., NAKANO, T., YOH, K., LIM, K.C., ENGEL, J.D. and TAKAHASHI, S. (2009). Transcription factor GATA-3 is essential for lens development. Dev Dyn 238: 2280-2291.

MAKLAD, A., KAMEL, S., WONG, E. and FRITZSCH, B. (2010). Development and organization of polarity-specific segregation of primary vestibular afferent fibers in mice. Cell Tissue Res 340: 303-321.

MAISON, S.P., LE, M., Larsen, E., LEE, S.K., ROSOWKI, J.J., THOMAS. S.A. and LIBERMAN,M.C. (2010). Mice lacking adrenergic signaling have normal cochlear resonses and normal resistance to acoustic injury but enhanced susceptibility to middle-ear infection. J Assoc Res Otolaryngol 11: 449-461.

MILO, M., CACCIABUE-RIVOLTA, D., KNEEBONE, A., VAN DOORNINCK, H. JOHNSON, C., LAWOKO-KERALI, G., NIRANJAN, M., RIVOLTA, M. and HOLLEY, M. (2009). Genomic analysis of the function of the transcription factor gata3 during development of the mammalian inner ear. PLoS One 4: e7144.

NARDELLI, J., THIESSON, D., FUJIWARA, Y., TSAI, F.Y. and ORKIN, S.H. (1999) Expression and genetic interaction of transcription factors GATA-2 and GATA3 during development of the mouse central nervous system. Dev Biol 210: 305321.

NICHOLS, D.H., PAULEY, S., JAHAN, I., BEISEL, K.W., MILLEN, K.J. and FRITZSCH, B. (2008). Lmx1a is required for segregation of sensory epithelia and normal ear histogenesis and morphogenesis. Cell Tissue Res 334: 339358.

OHYAMA, T., GROVES, A.K. and MARTIN, K. (2007). The first steps towards hearing: mechanisms of otic placode induction. Int J Dev Biol 51: 463-472.

PANDOLFI, P.P., ROTH, M.E., KARIS, A., LEONARD, M.W., DZIERZAK, E., GROSVELD, F.G., ENGEL, J.D. and LINDENBAUM, M.H. (1995). Targeted disruption of the GATA3 gene causes severe abnormalities in the nervous system and in fetal liver haematopoiesis. Nat Genet 11: 40-44.

PAULEY, S., WRIGHT, T.J., PIRVOLA, U., ORNITZ, D., BEISEL, K. and FRITZSCH, B. (2003). Expression and function of FGF10 in mammalian inner ear development. Dev Dyn 227: 203-215.

RAMAIN, P., KHECHUMIAN, R., KHECHUMIAN, K., ARBOGAST, N., ACKERMANN, C. and HEITZLER, P. (2000). Interactions between chip and the achaete/scute-daughterless heterodimers are required for pannier-driven proneural patterning. Mol Cell 6: 781-790.

RANGANATH, S. and MURPHY, K.M. (2001). Structure and specificity of GATA proteins in Th2 development. Mol Cell Biol 21: 2716-2725.

SIMMONS, D., DUNCAN, J., CAPRONA, D.C. and FRITZSCH, B. (2011). Development of the Inner Ear Efferent System. In Auditory and Vestibular Efferents, Vol. 38. Springer, New York, pp. 187-216.

VAN DER WEES, J., VAN LOOIJ, M.A., DE RUITER, M.M., ELIAS, H., VAN DER BURG, H., LIEM, S.S., KUREK, D., ENGEL, J.D., KARIS, A., VAN ZANTEN, B.G. et al., (2004). Hearing loss following Gata3 haploinsufficiency is caused by cochlear disorder. Neurobiol Dis 16: 169-178.

VANESCH, H., GROENEN, P., NESBIT, M.A., SCHUFFENHAUER, S., LICHTNER, P., VANDERLINDEN, G., HARDING, B., BEETZ, R., BILOUS, R.W., HOLDAWAY, I. et al., (2000). GATA3 haplo-insufficiency causes human HDR syndrome. Nature 406: 419-422. 


\section{Further Related Reading, published previously in the Int. J. Dev. Biol.}

See our recent Special Issue Animal Cloning \& Cell Reprogramming

edited by Michele Boiani and José B. Cibelli at:

http://www.ijdb.ehu.es/web/contents.php?vol=54\&issue $=11-12$

Patterning and morphogenesis of the vertebrate inner ear

Jinwoong Bok, Weise Chang and Doris K. Wu

Int. J. Dev. Biol. (2007) 51: 521-533

Mouse models to study inner ear development and hereditary hearing loss

Lilach M. Friedman, Amiel A. Dror and Karen B. Avraham

Int. J. Dev. Biol. (2007) 51: 609-631

Axial patterning in the developing vertebrate inner ear

Tanya T. Whitfield and Katherine L. Hammond

Int. J. Dev. Biol. (2007) 51: 507-520

Establishment of a proneural field in the inner ear

Gina Abelló and Berta Alsina

Int. J. Dev. Biol. (2007) 51: 483-493

Cellular commitment and differentiation in the organ of Corti

Matthew Kelley

Int. J. Dev. Biol. (2007) 51: 571-583

5 yr ISI Impact Factor $(2009)=3.253$
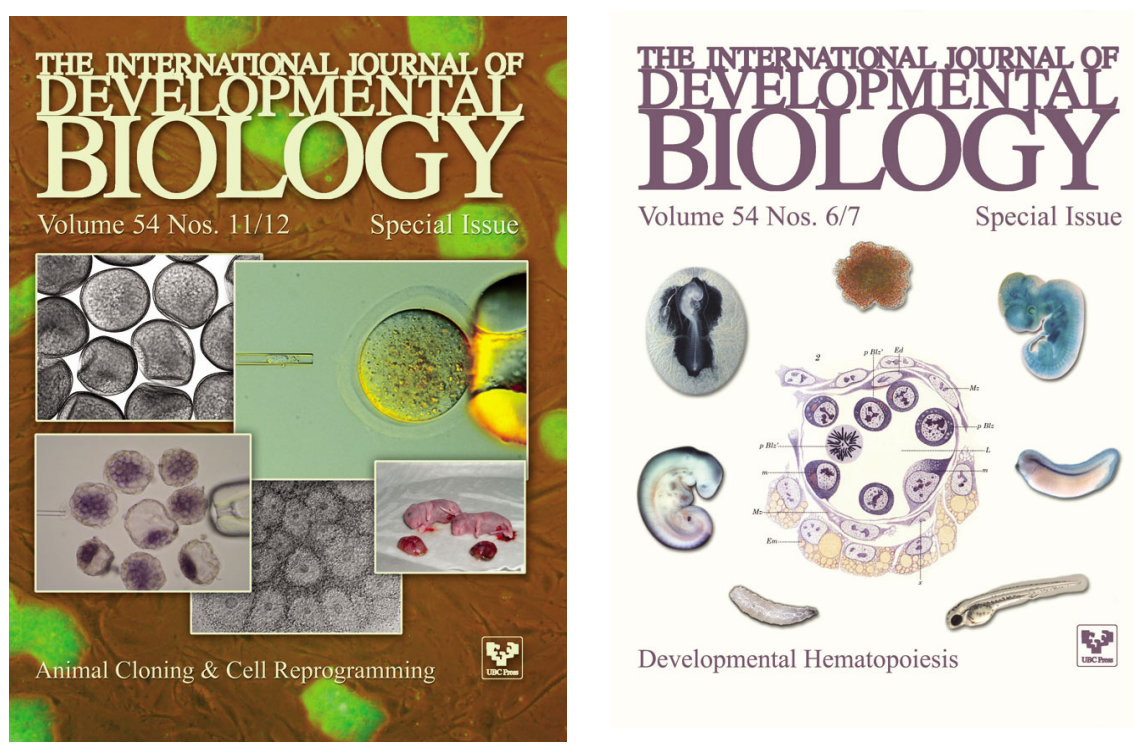

Volume 54 Nos. 6/7
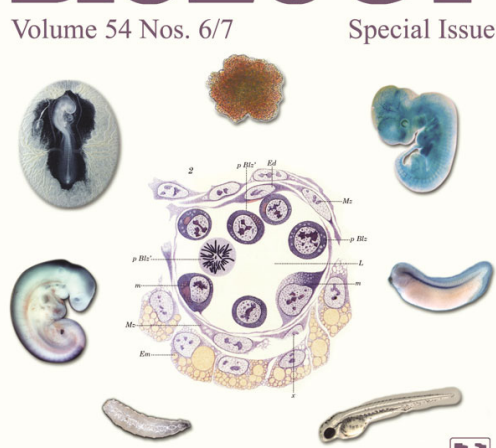

Developmental Hematopoiesis
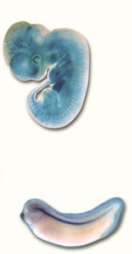

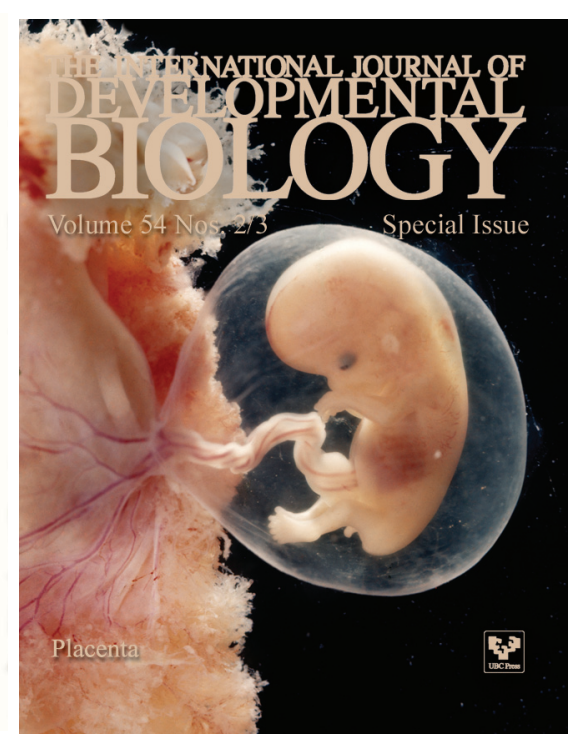

